\title{
Avaliação dos Impactos do Processo de Reconhecimento, Validação e Certificação de Competências (RVCC), em Indivíduos Residentes no Concelho de Arraiolos, no Período de 2000-2005"
}

\author{
Mariana Valério ${ }^{1}$ \& Lurdes Pratas Nico ${ }^{2}$
}

Resumo A presente comunicação surge no ämbito do Mestrado em Ciências da Educação: Especialização em Educação Comunitária e, com ela pretende-se apresentar os principais resultados da investigação realizada no âmbito de uma dissertação de mestrado. O trabalho concretizado incidiu sobre a "Avaliação dos Impactos do Processo de Reconhecimento, Validação e Certificação de Competencias (RVCC), em individuos residentes no concelho de Arraiolos, no periodo de 2000-2005", certificados pelo ex-Centro de RVCC da Fundação Alentejo - actual Centro Novas Oportunidades.

Num primeiro momento incidiremos sobre o objeto de estudo, de seguida caracterizamos o contexto de intervenção e o desenho metodolágico utilizado e, por último, apresentamos as principais conclusöes da investigação em très dimensöes (perfil dos respondentes, processo de Reconhecimento, Validaçăo e Certificação de Competências e impactos do processo de RVCC em várias dimensões).

Palavras-chave Educação e formação de adultos, aprendizagem ao longo da vida, reconhecimento, validaçăo e certificação de competências.

\section{O objecto de estudo}

O estudo realizado pretendeu avaliar de que forma é que a certificação formal das competências ocorridas nos individuos determinou os respetivos projetos de vida. A pesquisa pretendeu analisar os percursos subsequentes e a trajectória de vida dos adultos, resultante do processo de RVCC.

A escolha do tema prendeu-se com a pertinência do processo de RVCC, no panorama da educação e formação de adultos, em Portugal. Assim, o nosso estudo tem como objectivo conhecer, caracterizar e analisar as trajectórias de vida dos adultos, residentes no concelho de Arraiolos, no período de 2000-2005, nas dimensōes pessoal, profíssional e social, através da aplicação de um Questionário.

Embora existam diversos estudios a nivel nacional que problematizam esta temática, pareceu-nos pertinente abordar a mesma, num contexto territorial específica (concelho de Arralolos) por vários motivos: i) os baixos niveis de literacia; ii) a baxa qualificação dos ativos; iil) a inexistencia de um centro de

*. Comunicação decorrente do projecto de investigação cíentifica "As Novas Núpcias da Qualifcação no Alentejo" (Refa PTDC/CPECED/104072/2008) promovido pelo Centro de investigação em Educação e Psicologia da Universidade de Évora e financiado pela Fundaçäo para a Ciência è a Tecrologia/FCT.

1. Universidade de Evora (Mestranda do Curso de Mestrado em Ciências da Educação, Especialização em Educação Comunitária). E-mail: valerio.mariana@gmall.com

2. Universidade de Évora (Departamento de Pedagogia e Educação). E-mail: Ipnico@uevora.pt 
RVCC, no período em estudo; iM) a desertificação e a deficitária estrutura socioeconómica do concelho de Arraiolos.

\section{O contexto de intervenção}

Tal como foi referido, a área geográfica do estudo é o concelho de Arraiolos, que se encontra integrado na Região do Alentejo (distrito de Évora) e está delimitado por três grandes áreas de influência urbana: a Sul - Evora; a Este - Estremoze a Oeste-Montemor-o-Novo (figura 1). Este posicionamento geográfico tem condicionado, significativamente, o seu desenvolvimento, no que respeita à estruturação das áreas de actividade económica e à evolução demográfica, económica e social.

Figura 1-Concelhos do distrito de Évora

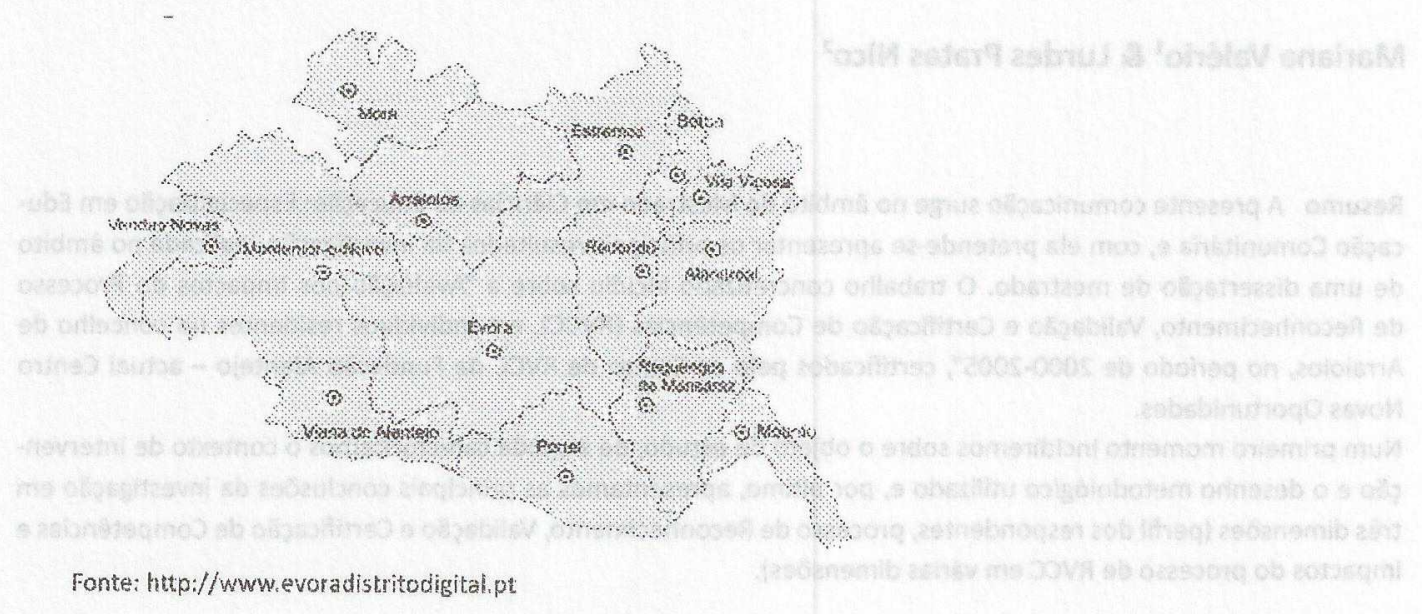

o concelho de Arraiolos sofre as consequências da sua interioridade, apresentando uma densidá. de populacional inferior 12 habitantes/Km2, sendo a média do Alentejo de 20 habitantes/Km2. Desta forma, "estamos perante um concelho que no contexto do País manifesta uma forte dominância rural apesar de, em termos relativos, não deixar de ser importante existêncla de alguma actividade industrial, mas que aparenta não ser acompanhada por idêntico peso proporcional, pelo menos em termos da composição empresarial, ao nivel dos serviços e do comércio" (Plano de Acção da Agenda XXI Local de Arraiolos, 2005:10) ${ }^{3}$.

O concelho possui uma área total de $684,06 \mathrm{Km} 2$, com uma população de $7363^{4}$ habitantes, repartido por sete freguesias - Arraiolos (IIhas e Santana do Campo), S. Pedro da Gafanhoeira, Sabugueiro, Igrejinha, Santa Justa (Vale do Pereiro), S. Gregório (Aldeia da Serra e Carrascal) e Vimieiro e está incluido na NUT ${ }^{5}$ III.

Arraiolos, entre 1991 e 2001, registou um decréscimo significativo da sua população residente $(-7,2 \%)$, situação que näo acompanhou o padrão nacional nem o regional onde o concelho se insere, já que a variação positiva à escala nacional é de $5 \%$ e a regional $0,2 \%$ (Quadro 1 ).

3. http://wwh.cmarraiolos.pt/NR/rdonlyres/0001067d/awivdvntisrexppbeadfppvlbreknhtize/agenda21.pdf, acedido em Maio de 2012 4. http://www.ine.pt/scripts/flex provisorios/Main.html, acedido em Maio de 2012.

5. Nomenclatura de Unidades Territoriais para Fins Estatisticos, com vista a estabelecer uma hamonia entre as divisães territoriais Esta nomenclatura tem vários niveis geograficos conforme o nivel de desagregação assumido, por exemplo: o nível ll, no continente, composto pelas unidades: Norte, Centro, Lisboa e Vale do Tejo, Alentejo e Algarve. 
Quadro 1 - Comparação entre a população residente por freguesia, 1991-2001

\begin{tabular}{l|l|l|l|l|l}
\hline \multirow{2}{*}{ Unidade Geográfica } & \multicolumn{2}{|c|}{1991} & \multicolumn{2}{c|}{2001} & Variacăo 1991-2001 \\
\cline { 2 - 6 } & Total & $\%$ & Total & $\%$ & $\%$ \\
\hline Arraiolos & 3599 & 43,9 & 3549 & 46,6 & $-1,4$ \\
\hline S. Pedro da Gafanhoeira & 679 & 8,3 & 623 & 8,2 & $-8,2$ \\
\hline Igrejinha & 824 & 10,0 & 769 & 10,1 & $-6,7$ \\
\hline Sabugueiro & 526 & 6,4 & 453 & 5,9 & $-13,9$ \\
\hline Santa Justa & 280 & 3,4 & 226 & 3,0 & $-19,3$ \\
\hline Säo Gregório & 529 & 6,4 & 396 & 5,2 & $-25,1$ \\
\hline Vimieiro & 1770 & 21,6 & 1600 & 21,0 & $-9,6$ \\
\hline rotofl do Concelho & 8207 & 100,0 & 7616 & 100,0 & $-7,2$ \\
\hline Alentejo Central & 173216 & - & 173646 & -- & 0,2 \\
\hline Portugal & 9867147 & - & 10356117 & -- & 5,0 \\
\hline
\end{tabular}

Fonte: Carta Educativa do Concelho de Arraiolos, Relatório final, 2006

Como anteriormente mencionámos, em termos demográficos e, comparativamente, com Portugal e com a região Alentejo, 0 concelho de Arraiolos caracteriza-se por uma forte recessão (Quadro 2$)^{6}$, pelos baixos niveis de literacia e pelo envelhecimento progressivo da sua população. A recessão começou por ser um reflexo dos fenómenos migratórios, apresentando-se, actualmente, como resultado de factores endógenos - crescimento natural negativo, incapacidade de actuação da população e criação de postos de trabalho.

Quadro 2 - População residente

\begin{tabular}{l|l|l|l}
\hline \multirow{2}{*}{ ANos } & \multicolumn{3}{|c|}{ Populaçäo Residente } \\
\cline { 2 - 4 } Portugal & 1991 & 2001 & 2011 \\
\hline Alentejo & 9.867 .147 & 10.356 .117 & 10.555 .853 \\
\hline Arraiolos & 782.331 & 776.585 & 758.739 \\
\hline
\end{tabular}

Fonte: INE, Dezembro 2012

Contudo, o concelho dispõe de uma boa rede de infra-estruturas de saúde, escolares e empresariais, sendo considerado um concelho com boas acessibilidades, e de bons equipamentos colectivos, 0 que 0 toma atractivo do ponto de vista da qualidade de vida, ainda que, tais factores não se tenham revelado suficientes para impedir a saida de jovens.

En 2001, a taxa de analfabetismo ${ }^{7}$, no concelho de Arraiolos, cifrava-se nos 17\%, apesar do concelho ter diminuido, significativamente, o número de analfabetos que medeia essa fronteira. Dos dados recothidos, verificámos que é a população da freguesia de Arraiolos a mais escolarizada, ainda que cerca de metade das pessoas que sabem ler e escrever detenham o nivel de escolaridade igual ou inferior a 19 ciclo e apenas $18,3 \%$ possuem o ensino secundário, médio ou superior (Gráfico 1).

6. http://www.cm-arraiolos,pt/pt/conteudos/o+conceiho/populacao/, acedido em Marco de 2012 .

7. Indicador que mede o peso que a populaçăo com 10 ou mais anos que não sabe ler nem escrever. 
Gráfico 1 - Incicadores de qualificação académica da população por freguesia

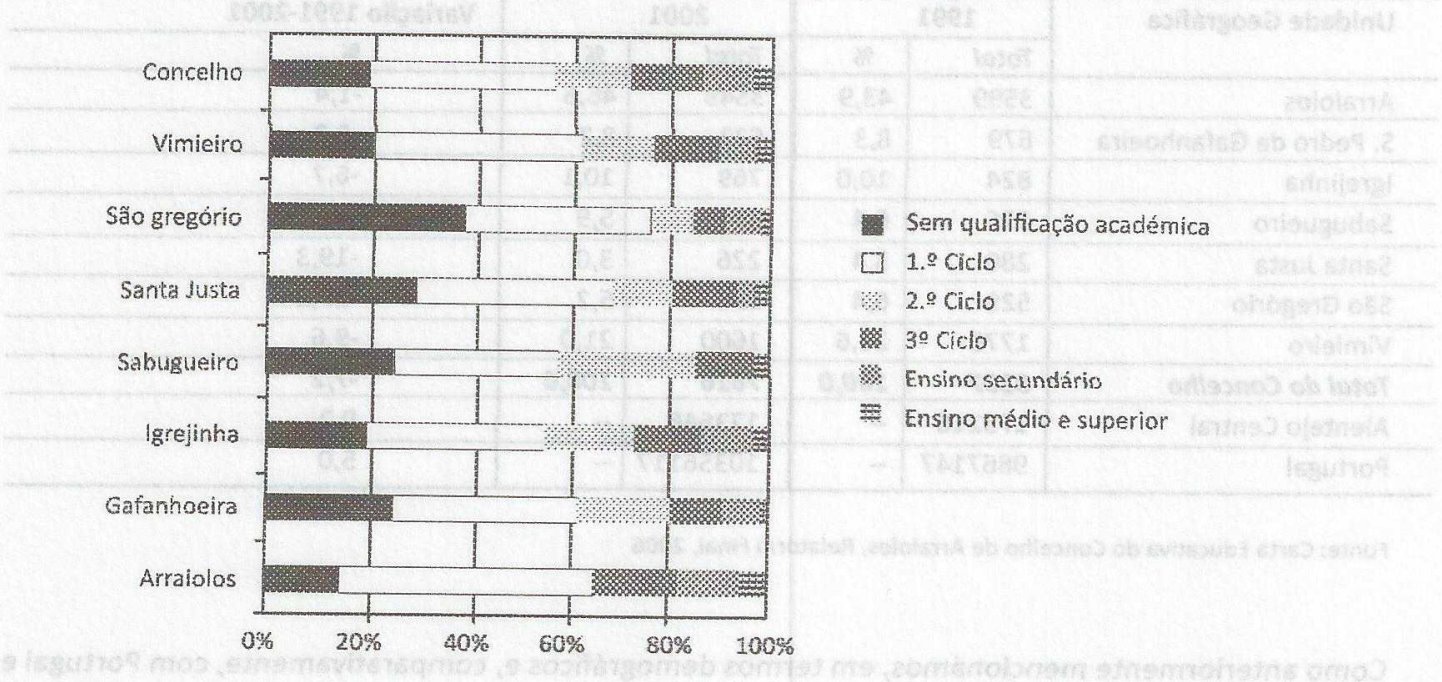

Fonte: Carta Educadiva do concelho de Arraiolos (2006:26)

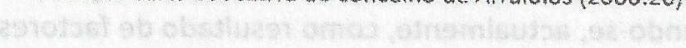

De salientar que há alguns documentos ${ }^{8}$, onde sáo efectuadas análises relativas à educação, que referem que o concelho acompanha a tendência nacional no que respeita à diminuição da taxa de crescimento natural da população em idade escolar, ao esforço de extensão do ensino pré-escolar, ao desenvolvimento das TIC e ao esforço da sua aplicaçăo no sistema de ensino. Apesar de, entre os dois momentos censitários, a população residente no concelho de Arraiolos ter melhorado na sua globalidade o seu nível de escolaridade ${ }^{3}$ o município continua 3 ocupar uma posição desfavorável, pois entre a população regista-se um domínio do 1.8 ciclo do ensino básico em comparação com os outros niveis escolares.

Este contexto não é alheio ao Agrupamento de Escolas de Arraiolos, o qual definiu uma estratégia de intervenção junto do público-alvo ao oferecer cursos tecnológicos diversificados em articulação com o tecido económica concelhio, em parceria com o Instituto de Emprego e Formação Profissional de Évora (IEFP), promovendo programas de orientação vocacional, assim como a constituição de um Centro Novas Oportunidades (CNO), em 2006.

Se nos debruçarmos, especialmente, na análise dos dados referentes à participação dos adultos no âmbito do processo de Reconhecimento, Validação e Certificaçăo de competências, entre 2000 a 2005 e, posteriormente, na análise dos dados a partir de 2006 (ano em que o concelho passou a dispor de um $\mathrm{CNO}$, verificamos que o número de certificações aumentou, gradualmente, conforme se observa no Quadro 3.

Quadro 3 - Número de Certificados do concelho de Arraiolos

\begin{tabular}{llllllll}
\hline Ano & 2007 & 2008 & 2009 & 2010 & $2011 / 2012(1)$ & TotAL \\
\hline Ne de Certificados & 173 & 131 & 71 & 81 & 183 & 639 \\
\hline
\end{tabular}

Fonte: DREAlentejo, 2012

(1) Os dados do ano de 2012 são os dados registados na plataforma SIGO, até 31 de Julho de 2012.

8. http://www.cmarraiolos.pt/NR/roionlyres/000oseec/esphrotycwhthikehinawdifmzevuga/PlanodeDesenvolvimentosocial.pdif. acedido em Máaio 2012 9. hitp://www cmarraiolos.pt/NR/rdonlyres/00ooseeb/ullyvtrdiaboengilffihmtaxbgviwur/CEdeArraiolos VersofinalNovembro2006
Corrigido.pdf, acedido em Maio de 2012 . 


\section{O Desenho Metodológico}

O presente estudo insere-se no Projecto de Investigaçăo "As Novas Núpcias da Qualificação no Alentejo" (PTDC/CPE-CED/104072/2008), financiado pela Fundação para a ciência e a Tecnologia (FCT) e promovido pelo Centro de Investigação em Educação e Psicologia da Universidade de Évora.

Na presente investigação assumimos a seguinte questão de partida:

De que forma é que a certificação formal das competencias ocorrida nos individuos residentes no concelho de Arraiolos, entre 2000 e 2005 , determinou os respetivos projetos de vida pessoais, profissionais e sociais?

Como objectivos gerais do estudo foram definidos os seguintes:

- Conhecer, caracterizar e analisar as trajectórias de vida dos aduitos residentes no concelho de Arraiolos, que concluíram o processo de Reconhecimento, Validação e Certificação de Competências, entre 2000 e 2005;

- Identificar o número de adultos residentes no concelho de Arraiolos, que concluiu o processo de RVCC, entre 2000 e 2005;

- Caracterizar o perfil dos adultos residentes no concelho de Arraiolos, que concluiu o processo de RVCC, entre 2000 e 2005;

- Avaliar o impacto pessoal, profissional e social da qualificaçăo, nas trajectórias de vida dos adultos residentes no concelho de Arraiolos, que concluiram o processo de RVCC, entre 2000 \& 2005.

A investigação incidiu num estudo de natureza descritiva, recorrendo-se ao uso de uma metodologia mista, isto é, análise quantitativa e qualitativa, reconhecida por alguns autores como uma mais-valia no campo da investigaçäo. Segundo Cupchik [2001 cit. por Duarte (2009)] "... as duas abordagens estão inter-relacionadas, contribuindo a pesquisa quantitativa para a identificação precisa de processos relevantes, e proporcionando a investigação qualitativa a base da sua descrição".

Os dados necessários para efectuar a investigação foram obtidos através de pesquisa documental e bibliográfica e, também, pela aplicação de um questionário.

No que respeita à aplicação do questionário, este foi enviado por correio, ou seja, o aduito respondeu ao questionário, sem a presença do investigador. Posteriormente, realizou-se a análise das trajectórias de vida dos adultos após a conclusão do processo RVCC, a partir da análise da informação disponibilizada pelo Questionário das Novas Qualificaçőes (ONa) ${ }^{10}$

As técnicas de análise de dados recolhidos foram alvo de análise estatística descritiva, de acordo com os procedimentos do SPSS (Statistical Pockage for the Social Science) (Pereira, 2008).

O universo do estudo foi constituído por 29 inquiridos. Para estes adultos foram enviados por correio postal o Questionário das Novas Qualificações (QNQ). Responderam aos QNO 24 adultos - a amostra da nossa investigação - que foram certificadas pelo ex-Centro de RVCC da Fundação Alentejo, no concelho de Arraiolos, alguns em regime de itinerância, no período de 2000 a 2005.

\section{Principais conclusões do estudo}

\section{A. Perfil dos respondentes}

- A maioria dos respondentes deste estudo é do género masculino $(62,5 \%)$ e casada $(66,7 \%) ; 45,8 \%$ têm 2 filhos e residiam, todos, no concelho de Arraiolos, distribuidos pelas 7 freguesias que constituem o concelho.

- A classe etária que reúne maior número de individuos é a que corresponde às idades compreendidas entre 31 e 40 anos $(33,3 \%)$.

$-91,7 \%$ dos respondentes estava empregado.

10. Instrumento que já estava construído e validado por um painel de especialistas, enquanto parte integrante do Projecto de investigaçäo "As Novas Núpcias da Qualificação no Alentejo". 
- Quanto às habilitações escolares dos respondentes (à data de aplicação do questionário), 58,3\% tinha o Nivel Básico - 3.9 Ciclo; $37,5 \%$ o Nivel Secundário e $4,2 \%$ tinha concluído já o Ensino superior (grau de Licenciatura).

\section{B. Caracterização do processo de RVCC}

Os adultos foram certificados pelo ex-Centro de RVCC da Fundação Alentejo, alguns dos quais em regime de itinerância.

Em 2002, os adultos começaram a frequentar o processo, registando-se, no ano de 2004, o maior número de inscriçöes no Centro de RVCC ( $45,8 \%$ - 11 adultos).

As conversas informais ("passa palavra"/redes de vizinhança) apresentaram-se como um dos meios mais importantes para a tomada de conhecimento do processo de RVCC $125,9 \%$ do total de resposta expressas\}. Este facto já havia sido referido por Nico (2009:429) nas conclusōes do seu estudo, sobre o impacto do processo RVCC nos adultos, no Alentejo, entre 2001-2005.

Quanto às razôes para a concretização do processo de RVCC, destacam-se os seguintes aspectos:

a) O papel que os respondentes atribuiram à valorizaçäo pessoal $(28,6 \%)$ quando comparado com outros itens. Em estudos anteriores (Nico, 2009:351) verificou-se que este impacto era muito relevante nos adultos certificados e que era perceptivel um aumento da autoestima, da satisfaçăo pessoal e da confiança em si próprios, o que promove a autonomia a a responsabilidade.

b) A melhoria de emprego e a obtenção de um diploma surgem em segundo lugar, com $14,3 \%$ do total de respostas expressas, respectivamente, o que demonstra a preocupação dos adultos em manter o emprego e, simultaneamente, apostar na qualificação.

O facto da dimensäo pessoal ser mais valorizada, poderá estar relacionado com a situação profissional dos respondentes, uma vez que a maioria se encontrava, àquela data, empregado. Logo, a preocupação com o emprego é secundária, mas este facto por si só não é conclusivo.

Os respondentes mencionaram que, durante a realização do processo, as malores dificuldades foram nas ăreas de competências-chave que constituem o Referencial de Competencias do Nivel Básico, nomeadamente nas áreas de Tecnologias da Informação e Comunicação, Matemática para a Vida e Inglês (esta última inserida na Linguagem e Comunicação) e a distância percorrida entre a casa e o centro.

\section{Impactos do Processo de RVCC [várias dimensões]}

No que diz respeito aos impactos do processo de RVCC, nas suas várias dimensões, apresentamos as principais conclusôes, no Quadro 4:

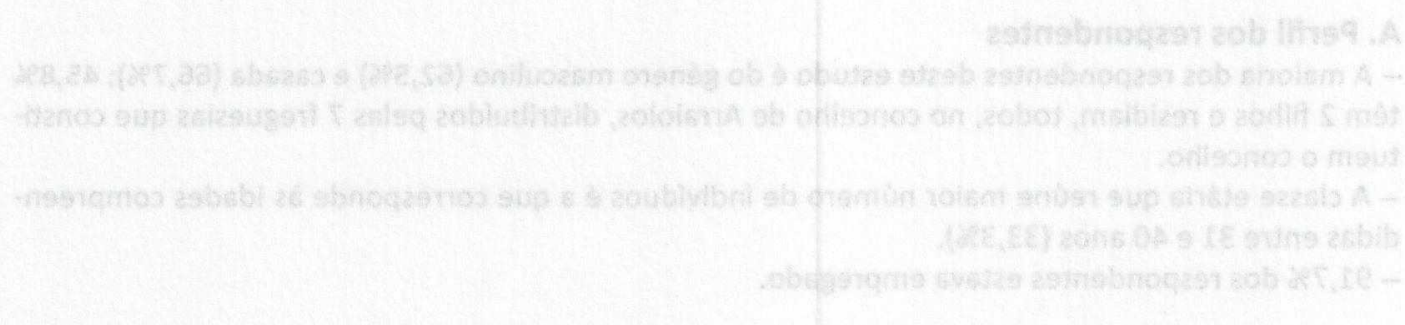

Avaliação dos Impactos do Processo de Reconhecimentc, Vaiidação e Certificação de Competências (RVCC) 209 em Individuos Residentes no Concelho de Arraiolos, no Periodo de 2000-2005_ Mariana Vatério \& Lurdes Pratas Nico 
Quadro 4-impactos do Processo de RVCC (várias dimensões)

\begin{tabular}{|c|c|c|}
\hline Itens & ANTES & Após \\
\hline Habilitaçöes académicas & $\begin{array}{l}\text { - } 50 \% \text { possula o Nivel B2 - } 60 \text { ano esco- } \\
\text { laridade. }\end{array}$ & $\begin{array}{l}\text { - No final do processo } 100 \% \text { obteve o Nivel } \\
93 \text { - } 99 \text { ano escolaridade. } \\
\text { - Após o processo, } 9 \text { adultos concluiram ou- } \\
\text { tros estudos (Alv). } \\
\text { - } 11 \text { adultos pensam vir a estudar } \\
(45,8 \% \text { ). }\end{array}$ \\
\hline Situą̧̧̃o profissional & $\begin{array}{l}\text { Maioria estava empregado/a }(91,7 \%) \text { e as } \\
\text { profissões eram diversificadas. }\end{array}$ & $\begin{array}{l}\text { - Alteração profissional em } 6 \text { respondentes } \\
(25 \%) \text { considerando que o processo RVCC } \\
\text { influenciou essa alteração. }\end{array}$ \\
\hline $\begin{array}{l}\text { Actividades de aprendi- } \\
\text { zagem }\end{array}$ & $\begin{array}{l}\text { - } 62,5 \% \text { individuos participava. } \\
\text { - Tipo de actividade mais valorizada: for- } \\
\text { mação Profissional }(53,8 \%) \text {. }\end{array}$ & $\begin{array}{l}\text { - } 22,5 \% \text { individuos continuou a frequentar } \\
\text { atividades de aprendizagem. } \\
\text { - Além da Formação Profissional }(52,4 \%) \text {. } \\
\text { destacam-se, ainda, as Palestras e Congres- } \\
\text { sos }(23,8 \%) \text {. }\end{array}$ \\
\hline Locais de aprendizagem & $\begin{array}{l}\text { - } 26,9 \% \text { das escolhas nos itens Centro de } \\
\text { Formação Profissional e Associaçoes de } \\
\text { Desenvolvimento Local, respetivamente. }\end{array}$ & $\begin{array}{l}\text { - } 33,3 \% \text { das escolhas no item "Outros" ("re- } \\
\text { direccionamento dos locais de aprendiza- } \\
\text { gem"). }\end{array}$ \\
\hline Uso do computador & 13 indivíduos $-54,2 \%$ & 21 individuos $-87,5 \%$ \\
\hline Uso da internet & 11 indivíduos $-45,8 \%$ & 22 individuos $-91,7 \%$ \\
\hline Autoconhecimento & $\begin{array}{l}\text { Não tinham "consciência" das suas capa- } \\
\text { cidades. }\end{array}$ & $\begin{array}{l}\text { Verificaram que eram "capazes" de voltar a } \\
\text { "estudar e/ou escola". }\end{array}$ \\
\hline
\end{tabular}

Assim, considerando a questão de partida traçada por esta investigação, concluímos que se registou uma melhoria significativa na vida dos adultos certificados, uma vez que thes permitiu alterar o seu nivel de escolaridade; facultou-lhes novas ferramentas que contribuiram para aumentar e melhorar as suas competências, operando transformaçăo nas várias dimensỏes (pessoal, profissional e familiar) e, consequentemente, na trajetória de vida dos respondentes.

\section{Referências Bibliográficas}

Duarte, T. (2009). A possibillade da investigação a três: refiexões sobre triangulaçõo (metodológica). Lisboa, CIES e-Working Paper n.60/2009.Disponivel em http://www.cies.iscte.pt/destaques/documents/CIES-WP60 Duarte..003.pdf. Acedido em 20 de Agosto de 2012.

Nico, L. (2009). Avaliação do(s) impacto(s) do processo de Reconhecimento, Validação e Certificação de Competências (RVCC), no Alentejo(periodo 2002-2005)[Tese apresentada à Universidade de Évora tendo em vista a obtençầo do Grau de Doutar em Ciências da Educação]. Évora: Universidade de Évora (policopiado).

Pereira, A. (2008). SPSS Guia Prótico de Utilização-Análise de ciados para Ciencias Sociais e Psicologia. Lisboa: Edições Silabo. 


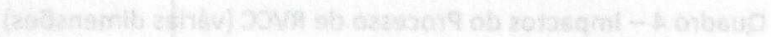

\begin{tabular}{|c|c|c|}
\hline 20794 & $2 \operatorname{son} 2$ & equstet \\
\hline 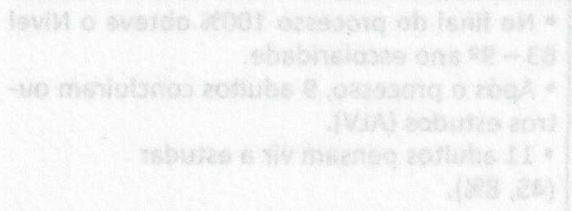 & 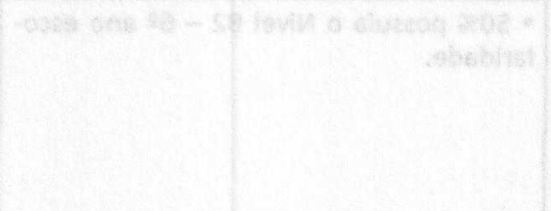 & 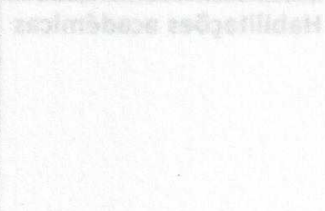 \\
\hline 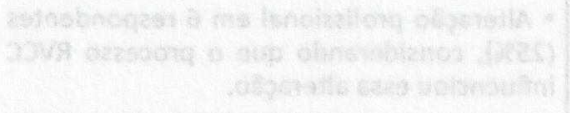 & 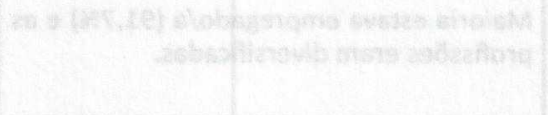 & 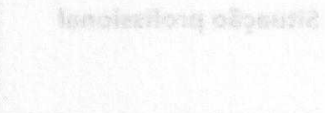 \\
\hline 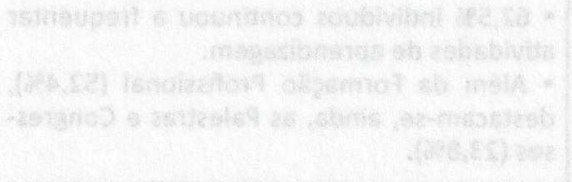 & 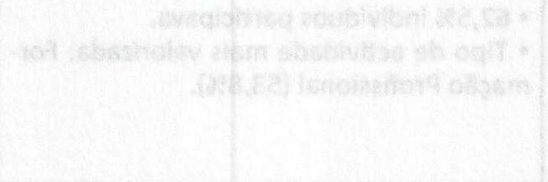 & 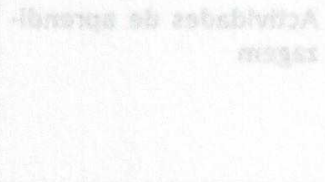 \\
\hline \multirow[t]{3}{*}{ 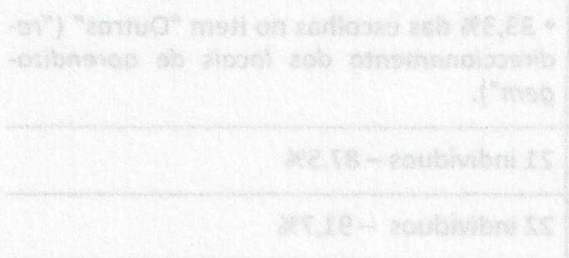 } & 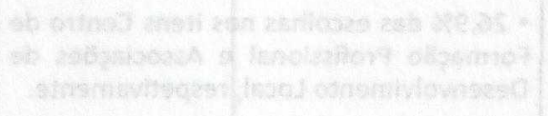 & 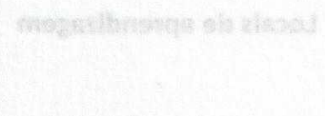 \\
\hline & & 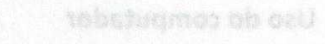 \\
\hline & 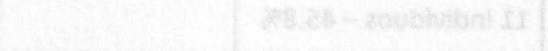 & 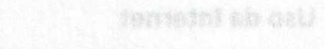 \\
\hline 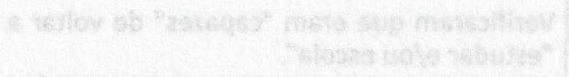 & 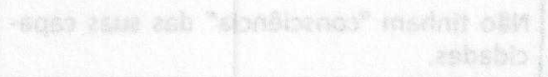 & 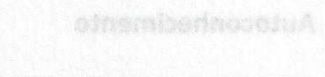 \\
\hline
\end{tabular}

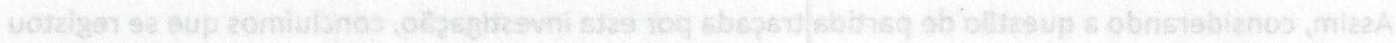

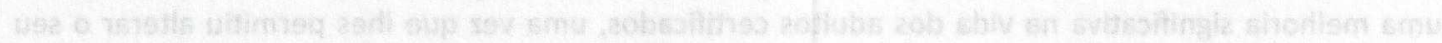

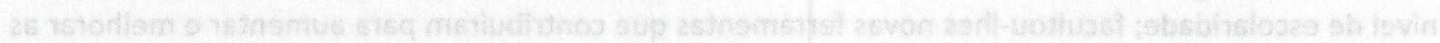

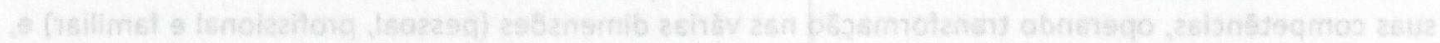

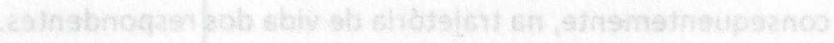

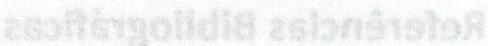

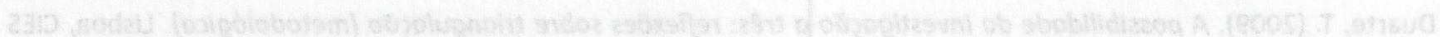

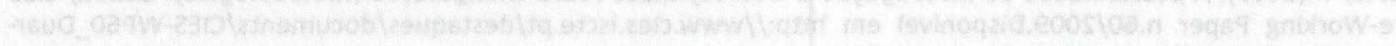

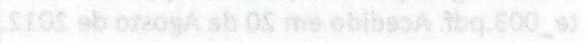

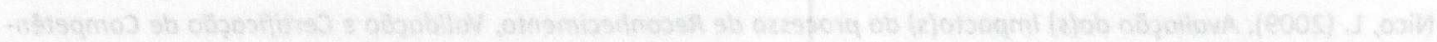

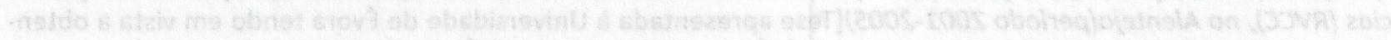

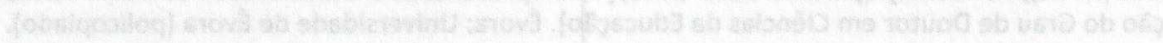

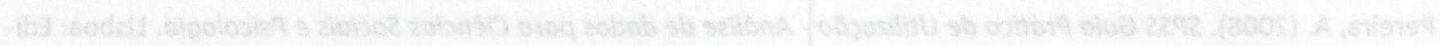

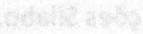

